\title{
As crianças protagonistas de notícias: sujeitos e objectos de crime*
}

\author{
Maria João Cunha Silvestre** \\ Cristiana Ferreira***
}

\section{Resumo}

O objectivo deste artigo é caracterizar o modo como as crianças são mencionadas nas notícias que protagonizam, avaliando a sua relação com casos de crime. Para o efeito foi aplicada análise de conteúdo a um corpus de 1321 notícias dos três jornais com maior tiragem em Portugal: Correio da Manhã, Público e Jornal de Notícias. Os resultados apontam para uma construção mediática da criança feita em torno de temáticas em que elas são protagonizadas sobretudo como sujeitos ou objetos de crime, numa retórica sensacionalista, que amplia a sua imagem de fragilidade enquanto vítimas ou de culpabilização social enquanto criminosos. Palavras chave: Criança. Notícia. Crime. Sensacionalismo. Jornais. Análise de conteúdo.

\section{Children in the news: subjects and objects of crime} \section{Abstract}

The aim of this paper is to characterize how children are mentioned in the news they lead, assessing its relation with crime cases. Content analysis was

\footnotetext{
* Conserva-se o português de Portugal.

** Investigadora do CAPP - Centro de Administração e Políticas Públicas e Professora Auxiliar na área de Comunicação, Instituto Superior de Ciências Sociais e Políticas (ISCSP), na Universidade de Lisboa, Lisboa, Portugal. Atualmente, atua como Professora Visitante na UNILAB - Universidade da Integração Internacional da Lusofonia Afro-Brasileira, em Redenção, Ceará, Brasil. Doutora em Ciências da Comunicação, na especialidade de Sociologia da Comunicação. E-mail:mjcunh@gmail.com

*** Investigadora do CAPP - Centro de Administração e Políticas Públicas, Instituto Superior de Ciências Sociais e Políticas( ISCSP), Universidade de Lisboa, Lisboa, Portugal. Mestre e Licenciada em Comunicação Social. E-mail: cristiana.imcf@gmail.com
} 
applied to 1321 news from the three major newspapers in Portugal: Correio da Manhã, Público and Jornal de Notícias. Results point to media construction of the child around themes where children lead as subjects or objects of crime, with a sensationalist rhetoric amplifying their image either of fragility as victims or of social blame as criminals.

Key-words: Children. News. Crime. Sensationalism. Newspapers. Content analysis.

\section{Los niños en las noticias: sujetos y objetos de criminalidad Resumen}

El foco del artículo es caracterizar como los niños son mencionados en las noticias, haciendo la evaluación de su relación con casos de criminalidad. Para tal hemos aplicado análisis de contenido a un corpus de 1321 noticias de los tres periódicos más grandes en Portugal: Correio da Manhã, Público y Jornal de Notícias. Los resultados indican una construcción mediática de los niños sobre temáticas donde ellos son protagonistas de crimen, como sujetos o como objetos. La retórica es sensacionalista, ampliando la imagen de fragilidad mientras víctimas o entonces mientras culpables.

Palabras clave: Niños. Noticia. Criminalidad. Sensacionalismo. Periódicos. Análisis de contenido.

\section{Introdução}

ctualmente, num mundo marcado por mudanças tão der-
radeiras onde os Meios de Comunicação Social detêm um
poder cada vez mais extenso, este tende muitas vezes a parecer desmesurado. Por vezes, avança-se para uma Comunicação bruta e feroz com efeitos que poderão ser perversos, sobretudo para aqueles considerados mais desprotegidos, nomeadamente as crianças, fragilizadas não só no momento da exposição relativamente aos conteúdos e imagens a que estão associados, mas também futuramente, podendo deixar marcas que os media não têm o poder ou a preocupação de sarar.

A infância é uma fase etária que corresponde a um período fundamental para o desenvolvimento social dos menores, quando são estabelecidas novas relações sociais, e onde é reformulada a sua visão e compreensão sobre o mundo (MALHO, 2003, p.54). 
Verifica-se, actualmente, uma contenda intrínseca à prática jornalística, referente aos casos sobre menores, entre o dever de informar, de denunciar e de expor - na qual não raras vezes são ultrapassados os limites éticos em prol da informação - e o dever de protecção face aos menores retratados. É uma luta entre o direito à informação e o direito à protecção da identidade e da dignidade humana. Para ajudar a encontrar respostas dever-se-á conhecer a forma como os menores são indicados nos media.

Este estudo tem como objectivo conhecer o modo como as crianças são mencionadas nas notícias que protagonizam, avaliando a sua relação com casos de crime. Especificamente desenvolvemos uma análise de conteúdo em três jornais com maior tiragem em Portugal para descrever e examinar o tipo de cobertura dos Meios de Comunicação a casos que incluem indivíduos com idade inferior a 18 anos, procurando com isto responder à questão: Qual a abordagem aos menores protagonistas de notícias nos conteúdos mediáticos portugueses e a sua relação com casos de crimes?

\section{A criança nas notícias}

A definição sociológica do conceito de criança está intrinsecamente ligada à percepção da realidade social dos mesmos, e, portanto, relacionada com a realidade construída e difundida pelos media.

As representações mediáticas são as fontes primárias de informação dos problemas da sociedade. Segundo Maley (2000, p.37) "em questões sociais e culturais, os diferentes media fornecem as principais plataformas para o debate, e a sua escolha de temas, protagonistas e opiniões moldam a agenda e muito do seu conteúdo". Isto é, a "opinião pública [...] depende assim de um mosaico de intervenientes, que encontraram dificilmente uma plataforma de entendimento sobre os valores inerentes à informação (RENAUD, 1996, p.33). Neste sentido, Ponte (2009) refere que as notícias produzidas pelos media em torno da infância surgem como um dos territórios de conhecimento onde têm lugar vozes organizadas, fontes públicas e institucionais de diferentes áreas e 
constituem uma porta de acesso privilegiado a temáticas que, de outra forma, estariam distantes de muitos indivíduos.

As variadas construções sobre o conceito de infância remetem para diversas formas de conhecimento da realidade social, reflectindo os passos de uma evolução entendida à semelhança de um percurso de vida que se vai manifestando nas múltiplas condições de ser criança em contextos histórica e socialmente definidos. Nas sociedades contemporâneas, as crianças são titulares de direitos próprios cuja negação ou violação poderá corresponder à aplicação de sanções (CARVALHO, 2006).

A representação mediática do menor está ligada sobretudo à representação da imagem do risco. Ou seja, muitos dos valores-notícia que empurram o menor para o espaço mediático estão ligados sobretudo a factos em que a integridade física ou moral está em risco. A valorização mediática do menor é então sobretudo "construída à luz de factores de natureza sociopolítica [...]. A representação social da infância moderna está enquadrada por um conjunto de princípios relativos ao exercício de uma cidadania plena que a todos sugere uma definição de bem-estar infantil" (ALMEIDA, 2001, p.20).

Verifica-se uma enfatização do processo de politização dos riscos com consequências morais e políticas (CARAPINHEIRO, 2001). Esta intensificação não se refere necessariamente ao aumento dos riscos, o que se verifica é a intensificação e alargamento da sua percepção. Mais do que o eventual acréscimo dos riscos sociais vividos pelos menores, aquilo a que se poderá estar a assistir nos dias de hoje será a um potencial aumento da sua representação no quotidiano, em função da crescente visibilidade que certos actos adquirem, em parte fruto de uma mediatização permanente (BECK, 1992).

Alguns sociólogos (GODDARD; SAUNDERS 2001, PONTE 2009) consideram que os jornalistas desempenham um papel fundamental na construção daquilo que é considerado "desviante" na nossa sociedade. Entendem que os jornalistas não reflectem meramente o trabalho das pessoas que lidam com o desvio na tentativa de o controlar, mas são, de certa forma, agentes do controlo 
social; uma espécie de elite definidora do desvio que articula os limites do comportamento na nossa sociedade. Isto levou a um escrutínio crítico do papel dos jornalistas na criação de imagens da criança em risco.

Investigar e reportar os problemas sociais, nomeadamente ligados a fenómenos de criminalidade, têm sido descrito como um dos mais desafiadores papéis do Jornalismo. Por exemplo, grande número de casos relacionados com abuso de menores apenas surgiu no meio mediático graças à persistência dos media. $\mathrm{O}$ Jornalismo de Investigação tem revelado uma contribuição fundamental na nossa compreensão do fenómeno do abuso infantil na sua verdadeira extensão (GODDARD; SAUNDERS, 2001).

A Comunicação Social coloca-se então ao serviço do reconhecimento dos direitos do homem e "os Meios de Comunicação favorecem de forma inequívoca a consciencialização mundial da universidade dos direitos humanos e a sua implantação prática e respeito real" (CRUZ, 1996, p.51).

No entanto, de acordo com Goddard e Saunders (2001), é fácil criticar a cobertura dos Meios de Comunicação Social relativamente ao abuso de crianças. Muitas podem ser feitas sobre o retrato dos media, no caso do abuso infantil, acusando-o de ser estereotipado, superficial e sensacionalista. No entanto, mesmo a cobertura sensacionalista poderá ter efeitos potencialmente benéficos, como o da sensibilização do público para o tema. Além disso, é também de destacar que muitas crianças têm de contar com os denunciantes e jornalistas para a protecção contra os abusos.

De facto, a avaliação da actuação dos Meios de Comunicação Social no retrato da criança sujeito ou objecto de crime revela que, maioritariamente, as histórias descrevem os menores ou como vítimas indefesas ou como delinquentes fora de controlo. Embora a vulnerabilidade e resiliência das crianças sejam focados num grande número de artigos mediáticos, há uma ênfase muito menor no retrato de crianças como cidadãos responsáveis, ou como indivíduos autónomos dotados de direitos.

Segundo Carvalho (2009), as crianças tornaram-se um pólo de atracção para os media, como vítimas e ainda como agentes 
de culturas de infância, mas sobretudo no centro de uma situação de risco social. Os problemas relacionados com criminalidade e a justiça criminal atraem tanto a atenção mediática por este tipo de publicações estar carregado de significação dramática, envolver vidas e propriedades e ao poder de promoção de fenómenos de medo.

As notícias sobre criminalidade e outros desvios sociais serão consideradas de topo nas agendas mediáticas (GODDARD; SAUNDERS, 2001). De acordo com Carvalho (2006), numa pesquisa longitudinal sobre a noticiabilidade das crianças na imprensa portuguesa de informação geral, entre 1970 e 2000, assinalou-se um notório aumento do número de peças nos anos mais recentes, 1995 a 2000, sobretudo centradas em questões de educação e de risco social. Emerge assim uma ambivalência entre a retórica de discursos públicos que fazem a apologia do ideal romântico da criança e do seu lugar na família, e as práticas políticas, económicas e sociais que dificultam o seu bem-estar.

A mesma prática de mediatização do desvio é levantada por vários autores. Santos refere a existência de vários estudos relacionados "com os efeitos do medo [...] junto de quem não tem experiência directa da realidade descrita, e que por isso depende em larga escala das mensagens sobre o assunto que são difundidas pela Comunicação Social (SANTOS, 1992, p.119).

Relativamente à linguagem, Goddard e Saunders (2000, p.44) defendem que nas descrições dos casos de abusos a menores são cada vez mais desprovidas de seriedade: "as ofensas sexuais a menores são frequentemente mencionadas de relacionamentos, o abusador e a vítima são indicados como tendo um caso, já tendo mesmo sido chamados de casal".

Os mesmos autores referem que este tipo de cobertura mediática tem efeitos inegáveis na sociedade. As representações mediáticas dos problemas sociais em geral e dos crimes em particular são relevantes não só no impacto que têm nas atitudes do público, mas também porque as histórias veiculadas são a principal fonte de informação para a maior parte das pessoas.

As limitações à Comunicação Social "têm como justificação primeira, não a concretização do interesse do público da admi- 
nistração da justiça, em ordem a uma eficaz investigação e acção processual de promoção e protecção, mas a tutela de direitos fundamentais da criança e do jovem" (BOLIEIRO, 2005, p.206).

$\mathrm{O}$ carácter normativo da lei surge como um instrumento de protecção também dos menores contra os abusos dos Meios de Comunicação de Massa: "é em alguma legislação que vamos encontrar uma preocupação pela representação das crianças" (PINTO; PEREIRA, 1999, p. 4). Estas normas destacam o papel dos media no enquadramento da cobertura jornalística da infância, trazendo uma série de preocupações pouco debatidas, como os direitos de participação, consentimento e audição das crianças e a difusão de informação relativa à prevenção de riscos sociais. Correspondem a linhas de orientação concretas pelas quais se devem guiar como a protecção da identidade e reserva da vida privada (CARVALHO, 2006).

No entanto, de acordo com o mesmo autor, se por um lado os media são vistos como perversos, ao focarem-se apenas nos casos mais grotescos do abuso infantil, por outro, parece claro que muitos escândalos e falhas dos sistemas de protecção de menores vítimas de abuso nunca teriam sido denunciados se não fosse a preocupação e os recursos dos media aplicados na sua investigação.

É neste sentido que este estudo exploratório coloca expectativas na análise dos conteúdos, para compreender qual o tratamento das crianças quando se tornam protagonistas e qual o posicionamento ético e jurídico face a esta realidade, ao reconhecer quais os elementos que identificam directa ou indirectamente os menores presentes nos relatos noticiosos.

$\mathrm{O}$ processo de escolha da temática deveu-se à necessidade de descortinar o tipo de protecção dada aos menores mediatizados, sobretudo porque o tema das crianças e as suas relações com cenários ligados à criminalidade comportam implicações sociais e científicas relevantes.

\section{Metodologia}

A pergunta de partida para este estudo com um desenho de pesquisa transversal, já que recolhe vários casos (notícias) 
comparados num dado momento no tempo (CAMÕES, 2012) é: Qual a abordagem aos menores protagonistas de notícias nos conteúdos dos principais jornais portugueses e a sua relação com casos de crimes?

No sentido de melhor orientar o estudo para conseguir responder à pergunta de partida que lançou esta pesquisa, avançaram-se as seguintes hipóteses:

H1: A inclusão de elementos identificativos directos e indirectos de protagonistas infantis nas notícias é uma prática comum;

H2: Os temas mais representados nas notícias com menores como protagonistas são os que os colocam numa posição de fragilidade face à exposição mediática;

H3: Os jornais de referência preocupam-se mais com a protecção de menores, cumprindo mais o Código Deontológico que os jornais sensacionalistas.

Para testar estas hipóteses desenvolveu-se uma análise de conteúdo das notícias onde figurem menores.

\section{Corpus}

Este estudo assenta na análise da imprensa diária em Portugal focando a utilização de elementos identificativos de crianças e jovens, com idade inferior a 18 anos. Procedeu-se à construção de uma amostra dos três jornais diários generalistas com maior registo de tiragens (www.apct.pt, consultada Fevereiro de 2010): Correio da Manhã, Público e Jornal de Notícias. Estas três publicações foram analisadas durante seis meses, num período iniciado a 01 de Março até 31 de Agosto de 2010, tendo sido feita recolha de todos os artigos cujas notícias tivessem como protagonistas indivíduos com idade inferior a 18 anos. No total dos seis meses foram contabilizadas 1321 notícias, distribuídas pelas três publicações, cujas histórias giraram em torno de indivíduos menores.

\section{Categorias e Unidades de registo}

Ao longo da recolha de dados procedeu-se à elaboração de um modelo que foi preenchido para cada notícia pertinente para 
esta investigação. $\mathrm{O}$ quadro conceptual foi construído em torno de quatro eixos: o da análise das peças jornalísticas em si, por meio das principais categorias identificadoras da notícia; o da análise do tratamento noticioso dado às notícias examinadas; da análise dos elementos que constituem a identificação directa do menor; e, por fim, o da análise de elementos que constituem a identificação indirecta do menor.

Assim sendo, foram analisadas todas as notícias de acordo com as seguintes temáticas: Abuso Sexual; Violência física e/ ou psicológica familiar; Violência física e/ou psicológica escolar; Negligência; Maus-tratos; Delinquência; Abandono; Pobreza; Tráfico Infantil; Exploração do Trabalho Infantil; Adopção; Disputa Familiar; Institucionalização Prisional; Institucionalização Reformatória; Institucionalização Hospitalar; Catástrofe/Guerra; Educação; Cultura; Saúde e Assistência; Segurança e Prevenção; Infanticídio; Homicídio; Desaparecimento; Acidente Mortal; Acidente Não Mortal e outros.

A segunda parte deste modelo destina-se ao reconhecimento do destaque e tratamento dado à informação publicada pelo jornal por meio da referência à secção, ao género em que foi formatada pelo jornalista, ao destaque dado na publicação, o número de páginas que ocupa, se é uma notícia repetida em edições anteriores, e que fontes contribuíram para a formação da notícia - aqui incluíram-se as agências noticiosas, outros Meios de Comunicação Social mencionados como fontes de informação, fontes desencadeadas em forças de segurança (polícias, bombeiros, polícia marítima, forças do exército, etc.), fontes oficiais (fontes estatais, membros do governo, dados de instituições acreditadas, etc.), organismos e figuras não oficiais (directores ou elementos acreditados de instituições relacionadas com o menor, advogados da família do menor, etc.), a própria criança, familiares da criança protagonizada na notícia, vizinhos do menor, testemunhas do caso relatado e outras fontes não categorizadas.

Analisaram-se ainda os jornais adoptando a designação "de referência” como os que, em observância a princípios deontológicos, por exemplo não identificam a identidade da vítima (ver 
CRUZ, 2002) versus os sensacionalistas, que procuram expor os factos com o maior impacto possível.

\section{Análise e discussão de resultados}

A análise dos resultados é apresentada de acordo com as hipóteses levantadas para este estudo.

\section{H1: A inclusão de elementos identificativos directos e} indirectos de protagonistas infantis nas notícias é uma prática comum no panorama mediático nacional

Relativamente aos elementos identificativos directos (ver Quadro 1) e à menção do nome das crianças na notícia como um dos principais elementos da identidade dos menores, verificou-se que esta prática era muito próxima dos 50\%. Um outro elemento é a referência ao nome dos seus familiares directos nas notícias. Esta menção, sobretudo quando se refere ao nome verdadeiro, pode levar facilmente ao reconhecimento do menor através da sua família, sobretudo nos meios onde esta se movimenta. Nos diários analisados verificou-se que na maioria das notícias publicadas a tendência $(50,7 \%)$ passa pela identificação nominal de um ou mais familiares directos da criança.

No que se refere à prática de acompanhar a notícia com foto do menor protagonista ou de elementos da sua família apurou-se que esta é uma minoria: 30,9\% das notícias eram acompanhadas por fotos de crianças e $26,9 \%$ dos casos por fotos dos seus familiares.

Além disso, conclui-se que a presença destes quatro elementos identificativos directos da criança nas notícias está fortemente ligada a factores como a publicação, o tema sobre o qual versa a informação, o género jornalístico e o tipo de destaque que a mesma recebe.

Quanto aos elementos identificativos indirectos (ver Quadro 2) do menor, um dos mais significativos é a especificação da sua idade. Este é um dado que poucas vezes os jornalistas descuidam, sendo que na maioria das vezes $(90,9 \%)$ é revelada a idade do menor. Este elemento é considerado essencial, pois aquilo que 


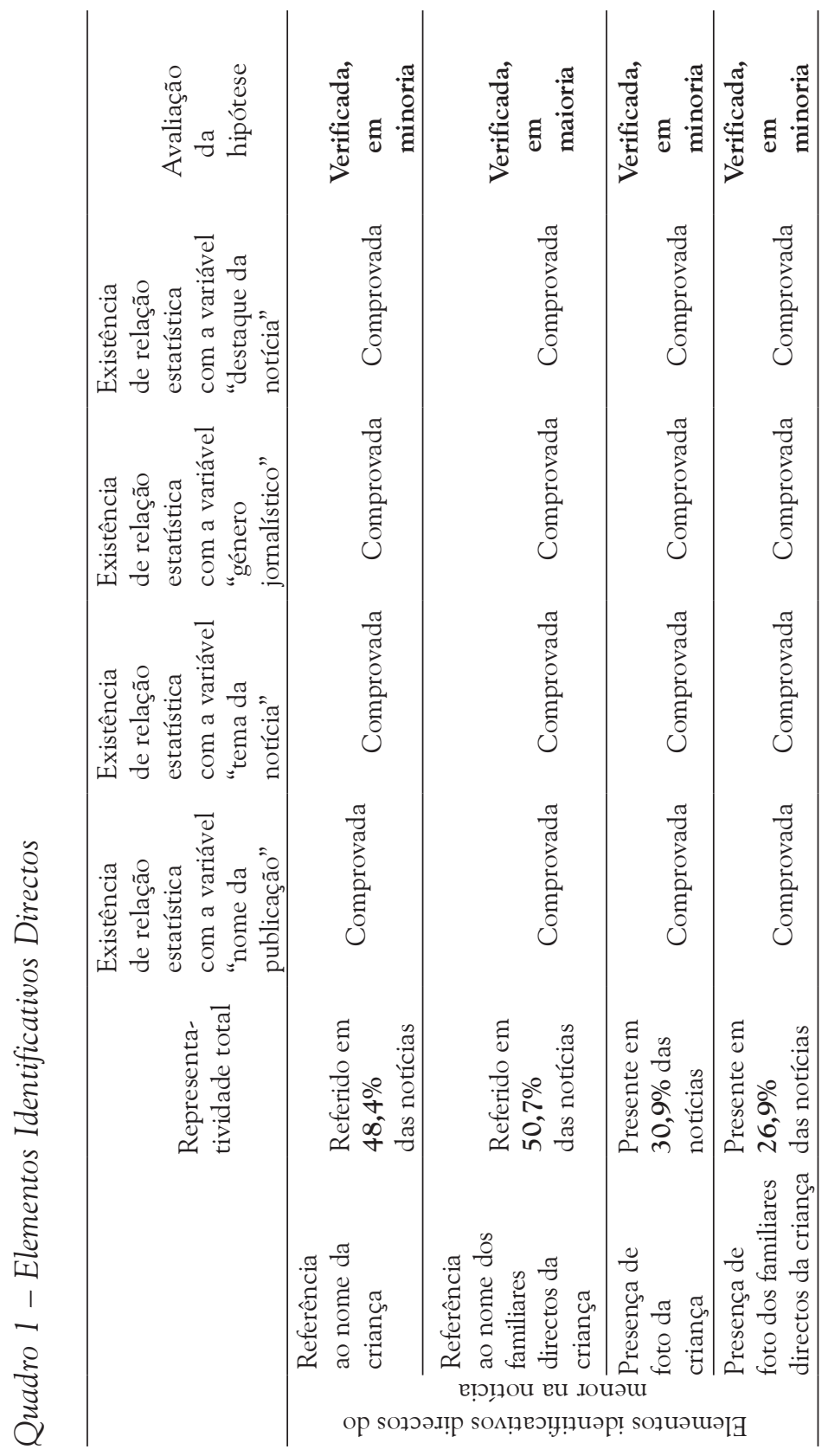


MARIA JOÃO CUNHA SILVESTRE; CRISTIANA FERREIRA

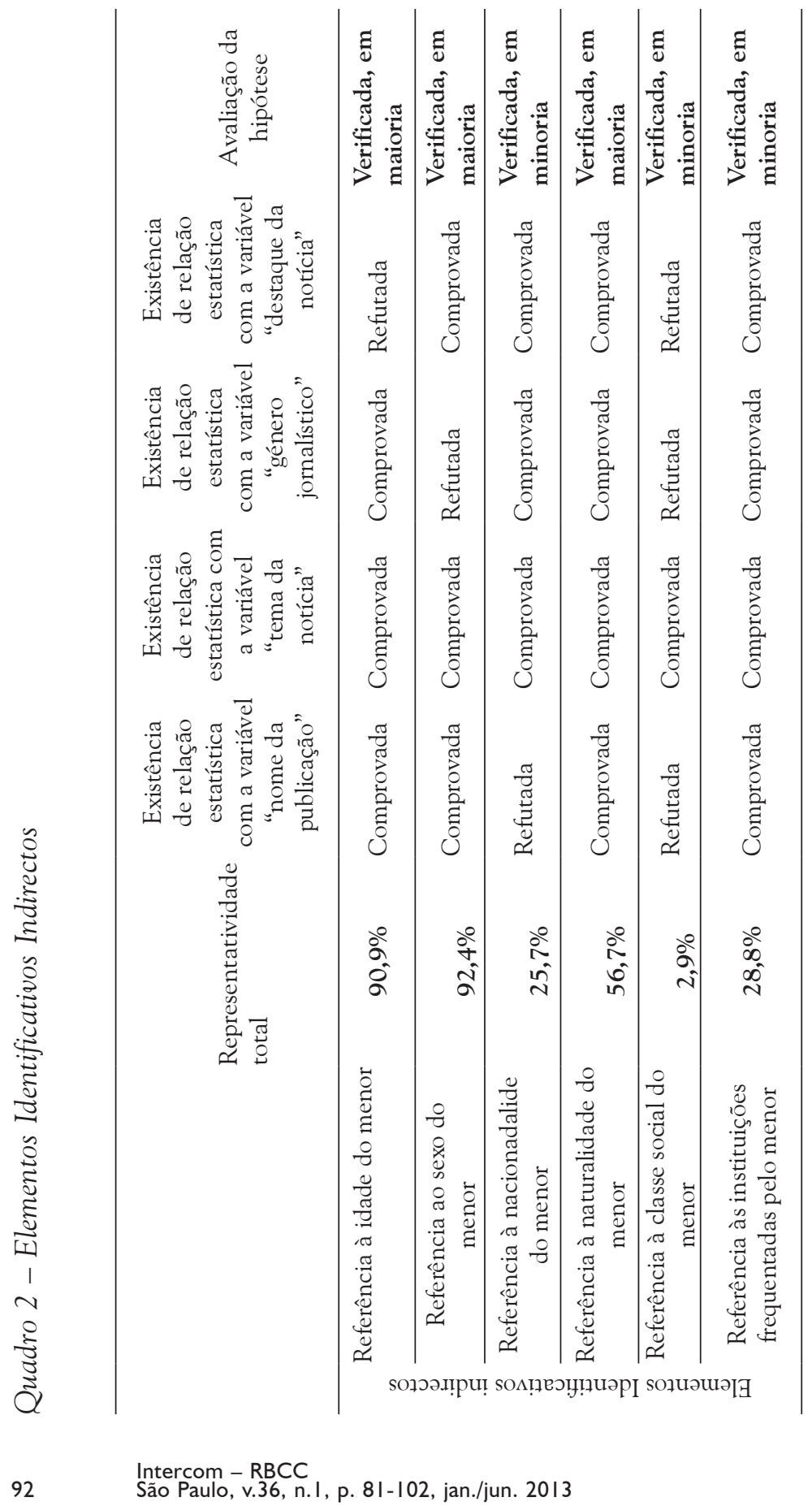


define um menor é precisamente a sua idade. A distribuição destas práticas de referência está relacionada com variáveis que definem as próprias características da informação, nomeadamente o jornal, o conteúdo informativo e o género jornalístico.

O sexo/género do menor é também considerado um elemento essencial à sua identificação, sendo de todos, o elemento que mais assiduidade tem nas notícias em que a criança é protagonista $(92,4 \%)$. A frequência da sua identificação está fortemente relacionada com factores como a publicação, o tema e o tipo de destaque.

A menção da nacionalidade como elemento da identificação indirecta do menor é efectuada em cerca de um quarto das notícias $(25,7 \%)$. Os principais factores explicativos das diferenças na prática desta identificação são o conteúdo temático da informação, o género jornalístico e o destaque da mesma no jornal.

Quanto à naturalidade do menor, conclui-se que este é também um dos dados mais utilizados $(56,7 \%)$, com diferenças justificadas pelos quatro caracterizadores da informação - nome do jornal, tema, género jornalístico e destaque.

Relativamente à menção da classe social do menor, conclui-se que este é um dos elementos identificativos indirectos mais dispensáveis, somente verificado em 2,9\% das notícias. A referência às instituições frequentadas pelo menor é também verificada em minoria (28,8\% das notícias), sendo que as oscilações desta prática estão relacionadas com factores como o nome do jornal, o tema da informação, o formato jornalístico e o destaque.

Estes dados confirmam a validade da primeira hipótese deste estudo, relativamente à presença de elementos informativos em relação à identidade da criança, quer de forma directa quer de forma indirecta.

\section{$\mathrm{H} 2$ : Os temas mais representados nas notícias com menores} como protagonistas são os que os colocam numa posição de fragilidade face à exposição mediática, nomeadamente relacionados com crimes

A análise relativamente aos temas das notícias em que as crianças apareceram representadas mostrou uma preponderância 
das peças sobre abuso sexual de menores. Tal como se pode verificar no Gráfico 1, em 21,1\% das notícias os menores apareceram representados como vítimas destes crimes de natureza sexual. $\mathrm{O}$ segundo tema que mais retratou os menores foi a delinquência, com 9,9\%. Em terceiro lugar (9,5\%), surge um tema não relacionado directamente com prática criminosa: os acidentes mortais envolvendo menores. Em quarto lugar encontram-se os casos de violência física e/ou psicológica escolar (9,3\%). Em 6\% das notícias analisadas figuravam casos de homicídio envolvendo menores de idade, e, com 5,9\% seguem-se os casos de acidentes não mortais, uma outra temática não directa ao crime.

Com frequências residuais aparecem temas como o infanticídio, a saúde e assistência, a educação, a cultura, os insólitos, os casos de violência física e /ou psicológica no seio familiar, a negligência, o desaparecimento de menores, a menção da criança como objecto de disputa familiar, a exploração do trabalho infantil, os maus-tratos e as catástrofes e guerras, a adopção, a segurança e prevenção, a pobreza, o tráfico infantil, e a institucionalização prisional, hospitalar e reformatória.

Ou seja, a maioria das notícias publicadas na imprensa portuguesa retrata crianças sexualmente abusadas, delinquentes e vítimas mortais de acidentes.

Gráfico 1 - Tema da notícia

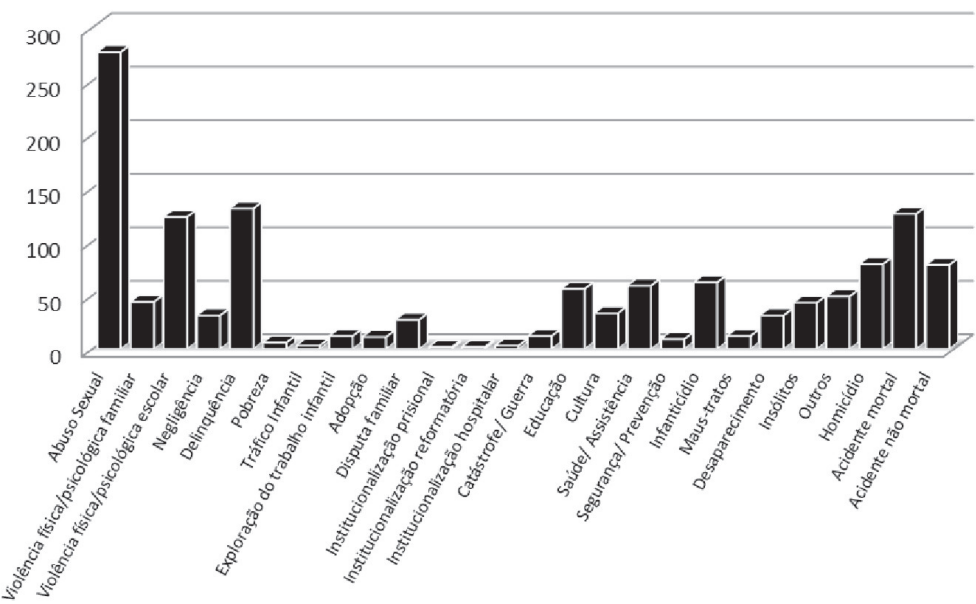


Pelas três principais temáticas depreendem-se as práticas mais operadas pelos media relativamente aos menores:

1) $O$ principal tema referido nos jornais, o abuso sexual, revela o menor como vítima de um crime hediondo, no qual o jornal parece assumir o papel de denunciante.

2) O segundo tema mais referido nos jornais é o da delinquência infanto-juvenil. Neste caso a situação inverte-se e o menor é revelado como culpado dos delitos cometidos. Esta tarefa de culpabilização é muitas vezes conseguida pela descrição pormenorizada dos crimes cometidos e complementada com uma alusão final à existência ou não de cadastro criminal do menor. São notícias nas quais o jornalista denuncia o menor, mas desta feita através da culpabilização e não da vitimização, com poucas referências sobre o contexto e a causa dos delitos.

3) Os acidentes mortais, apesar de representarem a criança como sujeito ou objeto de crime, deixam antever uma outra prática do Jornalismo: a exploração de notícias contra-natural e, muitas vezes, chocantes. A morte de crianças, sobretudo de forma acidental, é tida como socialmente pouco natural e muito mais difícil de aceitar que a morte acidental de um adulto. É uma norma intrínseca na consciência colectiva. Estas notícias esperam apelar ao leitor por contrariarem uma norma socialmente implantada, sobretudo se esta contiver pormenores que possam chocar a sensibilidade do público.

A análise dos dados vai então ao encontro da Hipótese 2, de que os menores protagonizados pelos três jornais diários mais lidos em Portugal saem para a esfera mediática principalmente como vítimas, seres frágeis cujo sofrimento atroz é infligido sobretudo por abusadores sexuais, familiares agressores ou mesmo assassinos, educadores negligentes ou simplesmente por acidentes, quer mortais, quer não mortais que o acaso os fez encontrar e esta fragilidade é aguçada pela inculcação social de imagens demasiado simplificadas da criança. Contudo, interessa ressalvar que há ainda grande preponderância de temas em que os menores são mediatizados como criminosos, delinquentes incorrigíveis, agressores irremediáveis. 
Resumidamente, para além de versarem especialmente sobre temáticas em que os menores surgem retratados como seres debilitados, a construção e disseminação deste retrato nos actuais formatos mediáticos fragiliza ainda mais a sua imagem. No seguimento da sujeição dos media à lógica de mercado, a construção de personagens informativas é feita em moldes simplificadores, nos quais a vítima e o vilão estão bem definidos, chamando o leitor a tomar um partido relativamente às várias personagens noticiadas, a formar um julgamento baseado nos seus instintos mais primários.

H3: Os jornais de referência preocupam-se mais com a protecção de menores, cumprindo mais o Código Deontológico que os jornais sensacionalistas

No seguimento das análises anteriores, foi constatado que a abordagem mediática aos menores é feita de forma muito homogénea, relacionada com a criação de rotinas nos processos do newsmaking nos dias de hoje, com a similitude temática das agendas dos diferentes media, bem como com a rendição destes temas a abordagens idênticas onde o sensacionalismo parece ser um dos principais factores de valorização noticiosa.

Porém, na análise às notícias dos três jornais identificam-se diferentes práticas dos media relacionadas com a abordagem sensacionalista e ou de referência assumida pelos próprios Meios de Comunicação.

Os valores do Gráfico 2 continuam a apontar para uma proeminência da temática dos abusos sexuais, independentemente do jornal e para a tendência dos jornais de assumirem o seu papel de denunciadores de crimes socialmente puníveis. A delinquência é também um dos temas de relevo, sendo o segundo mais abordado nas páginas do Correio da Manhã e o terceiro no Jornal de Notícias. No Público este é somente o oitavo tema mais referido. Em grande destaque encontram-se também as notícias de menores envolvidos em acidentes mortais. No Público e no Correio da Manhã este é o terceiro tema mais mencionado e no Jornal de Notícias as suas alusões ocupam o segundo lugar. A violência escolar é também um dos temas mais mencionados, contudo verificam-se algumas diferenças 
de publicação para publicação. Apenas no Público a violência física e/ou psicológica escolar ocupa o pódio em terceiro lugar das notícias mais aludidas. No caso do Jornal de Notícias e Correio da Manhã este não figura sequer como um dos três temas mais relatados.

O Correio da Manhã parece apostar em temas mais sensacionalistas e abordagens mais chocantes, relacionados com acidentes, homicídios, delinquência e violência escolar.

No Público, apesar de a maior parte do seu espaço ser consagrada aos mesmos temas, verifica-se que a tendência se desvia do Correio da Manhã, dando mais relevo a temas como a educação, a cultura e outros não categorizados. Neste sentido o Público parece distanciar-se dos alinhamentos das restantes publicações.

Relativamente ao Jornal de Notícias, é de referir a sua maior abrangência na distribuição temática. Apesar de se notar também uma certa tendência para seguir os temas mais impressionantes, verifica-se uma maior diversidade de temas como a educação, a violência escolar, o infanticídio, o acidente não mortal e o homicídio.

Gráfico 2 - Tema da Notícia vs Nome da Publicação

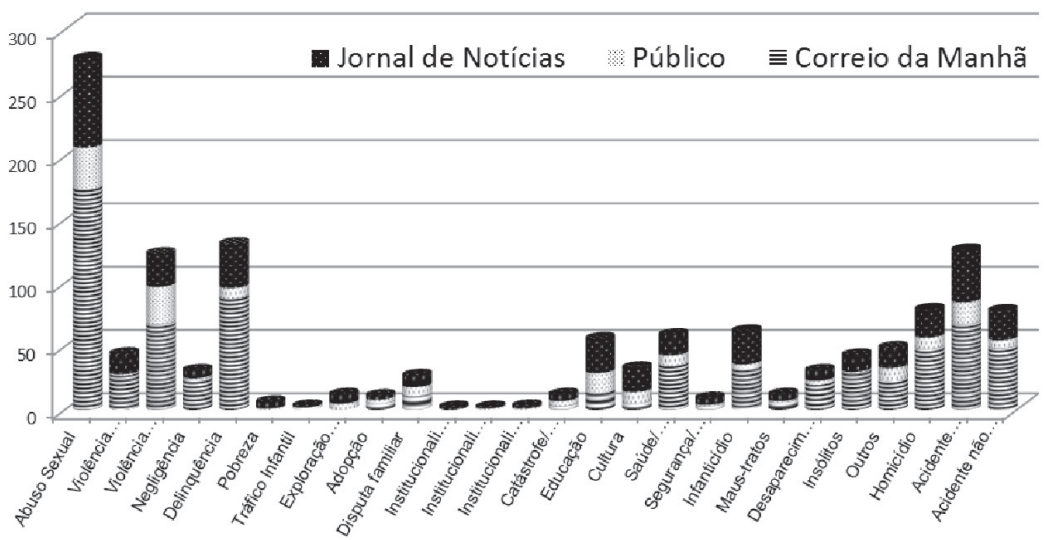

Para além da implicação do jornal, do tema notícia e do formato jornalístico, também o destaque que a notícia encontra no jornal determina a publicação ou não de fotos dos menores nos diários analisados. 
Nas notícias analisadas com direito a chamada de capa, em todos os jornais a maior tendência continua a ser a não publicação de foto do menor, porém verifica-se no Correio da Manhã e no Jornal de Notícias, muito mais que no Público, uma maior tendência para colocar na capa do jornal mais notícias com acompanhamento de fotos dos menores. A capa é o rosto de um jornal, a primeira ligação do leitor à publicação. Desta forma, a tendência dos jornais é de construírem uma capa apelativa que desperte nos leitores a curiosidade para descobrir qual o conteúdo da publicação. Muito deste apelo passa, não só pela impressão de títulos atractivos e escolha de notícias que despertem o interesse dos leitores, mas sobretudo através da imagem e daí a colocação da foto dos menores.

O Correio da Manhã e o Jornal de Notícias dão assim grande relevância aos argumentos de interesse humano nas notícias, muitas vezes com base num forte apelo emocional. Isto também pode ser verificado ao longo das várias manchetes e das chamadas de atenção de primeira e últimas páginas, baseadas numa linguagem quase sempre afirmativa e imperativa, à qual se alia, muitas vezes, um grafismo e uma certa violência, e quase inexistentes as peças nas secções nacional ou política.

Os cruzamentos das variáveis permitiram ainda verificar as especificidades da publicação de cada jornal relativamente à reincidência. É de salientar que o Correio da Manhã e o Jornal de Notícias dão prioridade às notícias não reincidentes; o Público preocupa-se em dar continuidade às histórias relatadas, publicando mais histórias reincidentes.

A análise empírica revela ainda uma tendência dos jornais na protecção de menores identificados na notícia, sobretudo quando ligados a casos relativos a abusos sexuais e delinquência. Contudo, esta tendência parece ser mais proeminente no jornal Público, havendo menor publicação de elementos identificadores directos de menores.

Esta análise corrobora a terceira hipótese da pesquisa. Isto é, o Público destaca-se por uma maior preocupação em não revelar elementos identificadores dos menores em temas devidamente 
expostos como atentatórios ao próprio Código Deontológico dos Jornalistas Portugueses e uma abordagem mais cuidada e objectiva, identificada no Jornalismo de referência.

Por outro lado, o Correio da Manhã surge como a antítese deste corolário. Verifica-se a cedência a uma retórica próxima do sensacionalismo, sendo que cada vez mais a notícia sobre crianças segue a tendência para a simplificação e uniformização das estórias mediáticas, com a espectacularização dos temas abordados, a procura do escândalo, a personalização superficial, a fragmentação imagética, a criação de estereótipos, preconizando a capitulação do jornal à abordagem tablóide dos conteúdos.

No Jornal de Notícias esta capitulação não é tão intensa como no Correio da Manhã. Contudo, mas não raramente cede à abordagem sensacionalista, ainda que de modo menos agressivo.

\section{Conclusão}

perigo da redução das crianças retratadas às imagens veiculadas actualmente pelos media e da inclusão destas no imaginário social da comunidade, tem consequências, não só para o público, cuja visão limitadora ao sensacionalismo o afasta da realidade em que vive, como também para os Meios de Comunicação Social, que se afastam também do seu corolário informativo, mas sobretudo, tem implicações nas crianças retratadas.

Tal como verificamos, os menores protagonizados pelos três jornais diários mais lidos em Portugal saem para a esfera mediática relacionados com crimes, principalmente como vítimas, seres frágeis cujo sofrimento atroz é infligido sobretudo por abusadores sexuais, familiares agressores ou mesmo assassinos, educadores negligentes ou simplesmente por acidentes, quer mortais, quer não mortais que o acaso os fez encontrar. Não com tanto peso, mas com alguma representatividade, surgem também os menores no papel de criminosos, delinquentes sem correcção, criminosos insensíveis, conflituosos agressores escolares, quer de colegas, quer de professores, institucionalizados incorrigíveis. Há quase sempre uma tendência para a construção de personagens simplificadas 
e os papéis alteram-se entre a vítima e o delinquente, em que a vítima surge com maior preponderância.

De facto, a avaliação da actuação dos Meios de Comunicação Social no retrato da criança revela que, maioritariamente, as histórias descrevem os menores ou como vítimas ou como delinquentes fora de controlo. Embora a vulnerabilidade e resiliência das crianças sejam focados num grande número de artigos mediáticos, há uma ênfase muito menor no retrato de crianças como cidadãos responsáveis, ou como indivíduos autónomos dotados de direitos.

Esta construção é feita por meio de elementos identificativos directos e indirectos, em que a idade e o sexo do menor surgem em maioria nas notícias veiculadas.

Contudo, constatou-se que, mais do que a reincidência de um ou outro elemento identificativo nas notícias em análise, a sua distribuição estava fortemente correlacionada às diferentes variáveis que caracterizavam as próprias notícias. Como tal, a prática da identificação dos jornais e a escolha pela revelação de um ou mais elementos relativos à criança depende dos conteúdos da própria informação veiculada.

Conclui-se então que há um claro desvio daquela que deve ser a conduta geral da imprensa face à protecção dos menores lançados às (es)feras mediáticas, em que os jornalistas se abrigam numa lacuna legal para a prática da identificação de crianças em casos que o direito devia garantir. Contudo, a lei não deverá ser o único garante da prática ética dos jornalistas e a mudança deverá vir também dos próprios profissionais.

Deverá ser privilegiada a educação e a formação para o Jornalismo, o aperfeiçoamento da deontologia, o desenvolvimento de secções de crítica dos media, o auto-controlo dos jornalistas, a acção das magistraturas. E incrementar meios que permitam ao jornalista entrar em ruptura com a máquina económica, a lógica mercantilista que o leva a seguir públicos desinformados, desligados da prática de interpretação da realidade, consumistas de conteúdos redutores, das notícias rápidas, descontextualizadas, cujo esforço de compreensão é simplificado. 


\section{Referências}

ALMEIDA, Ana N. de; ANDRÉ, Isabel Margarida; ALMEIDA, Helena N. de. Famílias e maus tratos às crianças em Portugal. Lisboa: Assembleia da República, 2001.

BECK, Urlich, Risk society: towards a new modernity. London: Sage Publications, 1992.

BOLIEIRO, Helena. A criança, a justiça e os média: algumas reflexões. Revista do CEJ, Lisboa, Dossier temático CEJ-25 anos, n.ํㅡㄹ, sl., p.193-219, 2005.

CAMÕES, P.J. O Design de Investigação. In: SILVESTRE, H.C.; ARAÚJO, J.F. (Coords.). Metodologia para a investigação social. Lisboa: Escolar Editora, 2012. p.103-120.

CARAPINHEIRO, Graça. A globalização do risco social. Porto: Edições Afrontamento, 2001.

CARVALHO, Maria João L. Crianças e jovens nas notícias - Juventude e Risco Social: uma Questão de Olhar(es), Lisboa: Faculdade de Ciências Socais e Humanas - Universidade Nova de Lisboa, 2004.

. Promoção e protecção dos direitos das crianças e dos jovens: uma Responsabilidade Partilhada, Oeiras: Comissão de Protecção de Crianças e Jovens, 2006.

. ; FERREIRA Levina. Infância e risco social: retratos da Imprensa Portuguesa. Oeiras: Sociologia, Problemas e Práticas, n.ํ6, p.105-129, 2009.

CÉSAR, Orlando, As vítimas de crime e os órgãos de Comunicação social Seminário, Lisboa: APAV, 2010.

CRUZ, João Cardoso da. Introdução ao estudo da Comunicação: imprensa, cinema, rádio, televisão e redes multimédia. Col. Epistemologia e Sociedade. Lisboa: Instituto Superior de Ciências Sociais e Políticas, 2002.

GODDARD, Chris; SAUNDERS, Bernadette J., Child abuse and the media. Melbourne: Child Abuse Prevention Issues, 14, 2001.

MALEY, Barry, The elite gatekeepers - How the media captures public policy, (Winter) Policy, St. Leonards, Australia, p. 33-38, 2000.

MALHO, Maria João, A criança e a cidade - independência de mobilidade e representações sobre o espaço urbano. 2003. Dissertação (Mestrado em 
Ciências da Comunicação) - Faculdade de Ciências Sociais e Humanas, Universidade Nova de Lisboa. Lisboa.

MOWER JR., A. Glenn, The convention on the rights of the child: international law support for children. Studies in human rights. Connecticut, Greenwood Press, 1997.

PINTO, Manuel; PEREIRA, Sara. As crianças e os media no pós-25 de Abril: discursos, percursos e silêncios. Braga: Saberes sobre as Crianças, 1999.

PONTE, Cristina. Crianças e jovens em notícias. Colecção Media e Jornalismo - 37, Lisboa: Livros Horizonte, 2009.

- AFONSO, Bruna. Crianças e jovens em notícia: análise da cobertura jornalística em 2005, em crianças e jovens em notícia: Actas do Seminário Infância, Cidadania e Jornalismo. Lisboa: Livros Horizonte, 2008.

PROTESS, D.L.; COOK, F.L.; DOPPLETT, J.C.; ETTEMA, J.S.; GORDON, M.T.; LEFF, D.R.; MILLER, P. The journalism of outrage: investigative reporting and agenda building in America. New York: The Guilford Press, 1991.

RENAUD, Michel, Ética e moral., ARCHER, L. BISCAIA J.; OSSWALD W. Bioética. Lisboa: Verbo, 1996.

SANTOS, José Rodrigues dos. Comunicação, o que é. Lisboa: Difusão Cultural, 1992.

SINGER, Dorothy G.; Jerome L. Handbook of children and the media. Thousand Oaks: Sage, 2001.

SOUSA, Jorge Pedro. Elementos de teoria e pesquisa da comunicação e dos media. Porto: Edições Universidade Fernando Pessoa, 2006.

TRAQUINA, Nelson. Jornalismo: questões, teorias e "estórias". Comunicação e linguagens. Lisboa: Veja, 1999.

VAN BUEREN, Geraldine. International documents on children, save the children. The Hague. Netherlands: Kluwer Law International, 1998. 